\title{
Pigmentation in Bristle and Horsehair
}

\author{
Sanford B. Newman
}

\begin{abstract}
Bristles for use in brushes are normally imported in large quantities for domestic consumption. Horsehair is also commonly used in brushes, often blended with bristle in paint brushes. To determine compliance with material specifications and to enforce labeling laws it is necessary to be able to distinguish between the two fibers. The need of a reliable method for identifying the two fibers became more critical after the start of hostilities in Korea, which increased the difficulty of obtaining bristle from Chinese sources.

The use of pigment distribution in bristle and horsehair has been recommended for their differentiation. However, the use of this characteristic has been challenged on the grounds of technical difficulty in the preparation of microscopic specimens and the possibility of variations in pigmentation at different levels in the fiber, in animals from different geographical locations, and in different types of hairs from the same animal.

As little previous attention has been given these points, a series of observations was made that show clearly that pigment distribution in fiber cross sections permits the detection of horsehair in bristle and bristle products. The test is, of course, applicable only to fibers that contain sufficient natural pigment to establish a distribution pattern. In addition, the medullation in the two fibers is sufficiently distinctive to constitute another aid in identification.
\end{abstract}

\section{Introduction}

The term "bristle" as used in the brush industry refers to the hair of swine exclusively [1]. ${ }^{1}$ References to the use of bristles in brushes can be found in the literature as early as the fifteenth century [2], and even today synthetics like nylon and neoceta have only begun to be substituted for bristle in paint and varnish brushes. Despite the large amounts of bristle consumed annually in this country, the greater part is still received from foreign sources, over 7,000,000 lbs. having been imported in 1950 [3]. Swine cannot be maintained profitably in the United States for the length of time necessary to develop long flexible bristles. A plentiful supply of cheap labor would also be required for the initial cleaning, sorting, and packaging if the domestic product were to compete with foreign bristle.

Because of this reliance on foreign supplies, the bristle trade has been subject to the exigencies of twentieth-century history. Before 1918 the Siberian and Russian bristles dominated the trade, but subsequently the Chinese product gained preference, especially in the premium types. The change was due, at least partially, to deterioration in the quality of preparation and dressing of the fiber for market. When the United Nations police action was instituted in Korea in 1950, Chinese bristle was abundant at reasonable prices, but soon after supplies dwindled and prices rose.

The failing supply of bristle was soon reflected in the number of adulterated brushes submitted for test to the Bureau. Brushes containing mixtures of bristle and horsehair, properly marked as to fiber content, are standard items usually available at lower prices than comparable brushes of pure bristle. More and more often it was found that brushes labeled pure bristle contained considerable quantities of horsehair. That this was a phenomenon of widespread occurrence was evidenced by the

\footnotetext{
${ }_{1}^{1}$ Figures in brackets indicate the literature references at the end of this paper.
}

number of queries on testing procedure that reached the Bureau from other Government agencies, from private testing laboratories, local purchasing organizations, and from individuals.

At the National Bureau of Standards, pigmentation pattern in the cross section of fibers is the chief criterion used in differentiating bristle from horsehair. This test is based on the original observations attributed to E. Weirick by Von Bergen and Krauss [4]. According to Krauss [5], Weirick observed the pigment distribution in fibers treated with a 10-percent sodium hydroxide solution. However, a number of questions were raised concerning the validity of the test by people in the brush and bristle trade and their consulting technical experts. These questions involved sectioning techniques and the possibility of variations in pigmentation at different levels in the fiber, in animals from different geographical locations, and in different types of hair from the same animal. For this reason the Bureau undertook to study these questions to determine the validity of the test method.

\section{Materials and Methods}

An attempt was made to secure samples of bristle and horsehair from as many representative sources as possible. Commercial bristle and horsehair were obtained from brush manufacturers and bristle suppliers. Other specimens from the files of the microbiological laboratory of the Bureau, mainly obtained from the larger manufacturers of brushes, were included in the study. In addition, a small amount of fiber was secured from animals in the surrounding area. Through the courtesy of the National Museum's Division of Mammals bristle and hair from hides of specimens of the families Suidae, Tayassuidae, and Equidae were made available. Tables 1,2 , and 3 , list the horsehair, bristle, and miscellaneous hair samples used in this work.

The Hardy microtome (fig. 1), a device used routinely in textile microscopy, was the means for 
TABLE 1. Bristle examined in cross section

\begin{tabular}{|c|c|}
\hline Sample & Source \\
\hline Black Hankow. & Commercial A. \\
\hline Black Hankow (received 1936) & Commercial B. \\
\hline Calcutta India & Commercial C. \\
\hline $\begin{array}{l}\text { Equador-South American } \\
\text { Bristle }\end{array}$ & $\begin{array}{l}\text { Do. } \\
\text { Commercial D. }\end{array}$ \\
\hline Black Bristle & $\begin{array}{l}\text { 9-month-old pig, Great Black strain, } \\
\text { U. S. Dept. of Agriculture, Belts- } \\
\text { ville, Md. }\end{array}$ \\
\hline Black Shanghai & Commercial A. \\
\hline $\begin{array}{l}\text { Superior Hankow, } 5 \text { in. (received } \\
\text { 1936). }\end{array}$ & Commercial E. \\
\hline Shanghai Black $\ldots \ldots \ldots \ldots$ & Commercial A. \\
\hline Black Bristle & Commercial D. \\
\hline $\begin{array}{l}\text { Mixed Bristle } \\
\text { Black Shanghai }\end{array}$ & $\begin{array}{l}\text { Brush, commercial D. } \\
\text { Commercial A. }\end{array}$ \\
\hline Persian & Commercial D. \\
\hline Sus scrofa attila (Persian wild hog) & $\begin{array}{l}\text { Smithsonian Institution Collection } \\
\text { U. S. National Museum Specimen } \\
\text { 283111. }\end{array}$ \\
\hline $\begin{array}{l}\text { Sus scrofa moupinensis (Chinese } \\
\text { wild hog). }\end{array}$ & $\begin{array}{l}\text { Smithsonian Institution collection } \\
\text { U. S. National M:iseum specimen } \\
\text { 172658. }\end{array}$ \\
\hline Sus cristatus rhionis (Crested hog) & $\begin{array}{l}\text { Smithsonian Institution collection } \\
\text { U. S. National Museum specimen } \\
122925 \text {. }\end{array}$ \\
\hline Sus barbatus (Bearded hog) - & $\begin{array}{l}\text { Smithsonian Institution collection } \\
\text { U. S. National Museum specimen } \\
196838 \text {. }\end{array}$ \\
\hline
\end{tabular}

TABLE 2. Horsehair (equus caballus) examined in cross section

\begin{tabular}{|c|c|}
\hline Sample & Source \\
\hline $\begin{array}{l}\text { Horsehair } \\
\text { Horsehair (flagged) } \\
\text { No. } 1 \text { stifi quality } \\
\text { Regular medium quality, black } \\
\text { Black mixture } \\
\text { Superior extra-stiff quality, black } \\
\text { No. } 2 \text { stiff quality, black } \\
\text { Black Australian } \\
\text { Horsehair (tail) } \\
\text { Horsehair }\end{array}$ & $\begin{array}{l}\text { Commercial } 1 . \\
\text { Do. } \\
\text { NBS collection. } \\
\text { Do. } \\
\text { Do. } \\
\text { Do. } \\
\text { Do. } \\
\text { Commercial 2. } \\
\text { 12-yr-old mare, USDA, Beltsville, } \\
\text { Md. } \\
\text { NBS collection. }\end{array}$ \\
\hline
\end{tabular}

TABLe 3. Miscellaneous hair examined in cross section

\begin{tabular}{|c|c|}
\hline Sample & Source \\
\hline $\begin{array}{l}\text { Hylochoerus meinertzhageni } \\
\text { (Suidae). }\end{array}$ & $\begin{array}{l}\text { Smithsonian Institution collection } \\
\text { U. S. National Museum specimen } \\
\text { 164627. }\end{array}$ \\
\hline $\begin{array}{l}\text { Pecari angulatus crusniger } \\
\text { (Tayassuidae). }\end{array}$ & $\begin{array}{l}\text { Smithsonian Institution collection } \\
\text { U. S. National Museum specimen } \\
11710 \text {. }\end{array}$ \\
\hline Equus grevyi (Equidae)...- & $\begin{array}{l}\text { Smithsonian Institution collection } \\
\text { U. S. National Museum specimen } \\
163238 \text {. }\end{array}$ \\
\hline Equus hemionus (Equidae) & $\begin{array}{l}\text { Smithsonian Institution collection } \\
\text { U. S. National Museum specimen } \\
\text { 84083. }\end{array}$ \\
\hline Equus przewalskii (Equidae)..... & $\begin{array}{l}\text { Smithsonian Institution collection } \\
\text { U. S. National Museum specimen } \\
\text { 260018. }\end{array}$ \\
\hline
\end{tabular}

sectioning all the samples, which contained 300 or more fibers. Because of the toughness of both bristle and horsehair it was necessary to soften the samples before they were cut. Although several organic plasticizers were tried, both hot and cold, none of them was as effective as a 10- or 15-min immersion in boiling water. After boiling the fibers they were placed in a microtome and sectioned in the usual fashion. The screw was advanced a $25 \mu$ increment for each section, but because the cut is made by hand the actual section thickness would be expected to vary to some extent from this figure. Sections were mounted on slides in Canada balsam. Single bristles or hairs were oriented in gelatin capsules, as shown in figure 2. The top and bottom of a No. 00 capsule was perforated with a hot needle and the fiber to be sectioned threaded through the two holes. A plug of gelatin or sodium carboxymethylcellulose was formed around the fiber where it passed through the bottom of the capsule in order to prevent leakage of the embedding material. If possible, the fiber was of such length that the cap could be withdrawn from the body of the capsule without unthreading the fiber from the cap.

The body of the capsule was filled with a mixture of monomers (8 parts of $n$-butyl methacrylate and 2 parts of methyl methacrylate) plus 0.5 percent of a catalyst, 2,4-dichlorobenzoyl peroxide. Polymerization was accomplished in an air-circulating oven held at $50^{\circ} \mathrm{C}$.

When polymerization was complete the gelatin containers were removed by soaking them in warm water. Mounting of the embedded fiber in the microtome was essentially by the method recommended for the ultramicrotomy of fibers [6], as shown in figure 3. Sections were cut at 10 or $15 \mu$ in the Spencer microtome. The methacrylate matrix was removed with toluol and the sections mounted in Canada balsam.

\section{Observations}

Typical cross sections of hog bristles (Sus scrota) from various sources are shown in figure 4 . Bristle pigment appears concentrated or more dense in the center of the cross section and becomes more dilute as the periphery is approached. Certain fibers in any sample of bristle exhibit cross sections with more or less jagged fractures, usually through the center of the section. It is a common observation that many bristles have hollow centers, and these hollows or fragmentation medulla probably account for most of the gaps noted in the cross sections. Occasionally these openings will practically divide the sections into two halves, and in these cases it is suspected that the sectioning procedure is responsible for, at least, enlarging these fragmentation medullas. In general, the bristle medulla is totally devoid of fibrous material but, more rarely, fragments of the surrounding cortical cells can be found in the opening. Where fragmentation medullas are present, the pigment will appear more concentrated around the edges of the void and will diminish toward the peripheral cuticle.

Central concentration of pigment was found in all bristles, regardless of their geographical origin. Rarely, a radiate variation of the pigmentation pattern can be found. In this, the pigment is limited to bands that in general are thick at the center and narrow toward the border of the section, as shown in figure 5.

The genus Sus consists of numerous closely allied and slightly differentiated forms. Transportation by man has further confused the taxonomy. However, it appears that there are at least three groups of wild hogs of more than subspecific rank [7]. Several dozen bristles, representing all these groups, as well as widely separated geographic races of one 
of them, were taken from hides in the Smithsonian Institution and were sectioned and examined (see table 1). The pigmentation pattern was found to be the same in all specimens, as noted in commercial bristle from domestic hogs.

Hylochoerus meinertzhageni (African Forest hog) a member of the Suidae, or Pig family, exhibits the normal bristle pigmentation pattern (fig. 6). Cross sections of the hair of the peceary (Pecari angulatus crusniger) were examined and found to have a much different and distinctive pattern (fig. 7). The medulla is much more diffuse, and the medullary cell outlines are easily distinguished. Pecari $a$. crusniger is included in the Tayassuidae, a family closely related to the Suidae.

Pigmentation at various levels in a bristle appeared to be subject to some variation in density, but the basic pattern did not change. Sections through the part of the bristle enclosed in the root sheath (fig. 8) showed the same pattern found at other levels in the fiber. When sections were taken through the branching flagged portions of the bristles the pigmentation pattern was more difficult to detect. Cross sections of flags appeared as fragments or segments of the entire bristle section. The opacity of sections through the flagged area is often comparatively high.

Hog wool is the curly, rather fine fiber usually found growing on the belly area of the hide. Hog hair is the name applied to the poorly defined fiber that is intermediate between bristle and wool. Wool is rarely found in brushes, being a waste product destined mainly for upholstery use, but hair is largely blended with the brush bristle. When examined in cross section, however, both wool and hair were found to have the pigmentation found in bristle, as shown in figures 9 and 10 .

Mane hair and tail hair of the domestic horse (Equus caballus) are widely used in many brushes. The body hair is generally too short for this type of application. Tail hair is thicker in cross section than mane hair, and the Federal Specification [8] arbitrarily defines any sample having an average diameter of not less than 0.0055 in. as tail hair. In cross sections, however, both tail and mane hair revealed the same pigmentation pattern. It differed from bristle in possesing a cellular medulla, with little or no pigment, which occupied the center portion of the hair cross section. The pigment granules were in a ring around this colorless area. The medulla was only roughly circular; fingerlike diffuse projections of pigmented cells into the colorless areas were common, and colorless projections into pigmented areas were often seen. Typical cross sections through samples of horsehair are shown in figure 11.

As in bristle, the sections of horsehair revealed minor variations in density and distribution of pigment granules at different levels, but the basic pattern was constant. In figures 12,13 , and 14 are views of sections cut from different locations on the same hair.

Other members of the horse genus appeared to have essentially the same pigment distribution. Hairs from Grevy's zebra (Equus grevyi), the Asiatic wild horse (E. przewalskii), and Asiatic wild ass ( $E$. hemionus) all show peripheral concentration of pigment granules in cross section (figs. 15, 16, 17).

Pigment was not seen in sections of the cuticle, or scale, structure in either bristle or horse hair. 'The cuticle of bristle appeared much thicker than that of horsehair and formed a refractive ring around the entire section. The pigmentation did not come quite to the outer edge of the cortex in all fibers, and in cross section such fibers had the superficial appearance of possessing an extremely thick cuticle. However, the true cuticle could be easily distinguished by the difference in its index of refraction.

The dyeing of light-colored, or unpigmented, bristle and horsehair is a common practice in the manufacture of brushes. The presence of dye in the fibers could be easily detected in cross section and presented no obstacle to the determination of pigmentation pattern. Natural pigment was always present in the form of discrete melanin granules. Dye, on the other hand, could always be seen in cross section as a band of amorphous color of varying width. In many cases the band appeared to be localized and discrete, forming a ring concentric with the section outline. In other cases, however, there would be almost complete penetration of dye throughout the section. Sections of dyed horsehair are shown in figure 18 .

The artificial flagging of horsehair appears to be a fairly common practice in the brush industry. Flagged horsehair is sometimes found in brushes labeled bristle and, more often, in brushes containing mixtures of horsehair and bristle. Synthetic flags, as would be expected, were found on fibers with little or no taper. All the branches of the flag at the tip of the hair appear to spring from practically one point on the length of the fiber and many branches, often a dozen or more, were found in a flag. At the point where the fiber is broken up into these branches the hair appears to increase in diameter. Natural flags contained fewer branches, and these divided at different levels from the main trunk. Examples of these flags are shown in figure 19 .

The outline of the cross sections of both bristle and horsehair ranged from roughly circular to elliptical and included many irregular shapes.

\section{Discussion}

Microscopic examination of fiber is apparently rarely resorted to in the brush and bristle trade. Great reliance is placed on the so-called "eye and feel test", which some use not only to identify bristle but also to determine its geographic origin. Other individuals using this test are more moderate in their claims. Visual examination and manipulation of the fibers is the basis of this test method.

Several men with 20 or more years of experience in the brush and bristle trade consented to apply the eye and feel test to a brush shown to be adulterated by cross-sectional examination (fig. 20). Many of the samples extracted from the brush, which were 
identified by the experts as representing fibers from a specific geographic source, were extremely small, but in almost all cases sectioning revealed the horsehair pigmentation pattern in some of the fibers chosen. In one case two fibers were selected to represent Tientsin bristle, and one of the fibers showed the horsehair pattern. It is difficult to define the criteria used in such a nonmicroscopic test. Flexibility and surface appearance are often mentioned, but it is interesting to note that most errors in judgment are made on the finer and untapered fibers that are in the problem group. Evidently taper, fiber diameter, and probably flagging must be elements in the precision of this test.

The microscopic observations previously described indicate that the centric pigmentation pattern is characteristic of bristle, whereas the concentric pattern is characteristic of horsehair. Centric pigmentation appears not to be restricted to the domestic Sus scrofa but is probably common to all of the Suidae. Similarly, the concentric pattern of pigmentation was found in the hair of all members of the genus Equus that were studied. In view of this taxonomic distribution, it is hardly conceivable that geographic origin would affect the pattern.

Von Bergen and Krauss [4] found that all bristle fibers have a medullary channel. Although medullated fibers were not uncommon in the samples examined, they were not as numerous as the nonmedullated, and most of the medullas were of the fragmentation type. In unpigmented, or colorless, bristle, however, medullation appears more common.

The sectioning of bristle and horsehair presents no great problems in technique. In sectioning with the Hardy microtome, a fresh single-edge razor blade is used for cutting each section. Drying out of the wet fibers causes a gradual return to their normal toughness, so that sectioning should be performed as expediently as possible. With methacrylic embedding and the Spencer microtome, 6 to 12 fibers can be cut at $10 \mu$ or less if desired.

Bristle and horsehair are too opaque to permit microscopic examination without sectioning. Weirick's method of treating fibers with a 10-percent solution of sodium hydroxide enabled her to detect the pigmentation pattern through the fiber diameter. Treatment with alkali, however, leads to the degradation of the fiber and does not permit critical observation of detail. Moreover, it gives no information on the presence or absence of dye.

Hardy and Hardy [9] have tabulated some trade categories of commercial paint-brush fibers, giving their most notable characteristics. A typical bristle has a definite taper, being thicker at the butt, or root, end and becoming gradually thinner toward the tip. Near the tip end the bristle becomes furcated, often dividing into several branches, to form the flag. Bristles that approximate this description are easily distinguished from horsehair by their gross aspect.
Horsehair has no definite taper, though it may vary in diameter over its length, and it has no natural flag. The average diameter of bristle at the base is greater than the average diameter of horsehair [3].

In all groups of bristles, selected at random, however, there are fibers showing little or no taper, a complete lack of flag, or both. Flags may fail to form, be worn off while still on the animal, or be removed in processing. It is these bristles, often making up a considerable part of the whole, which present a problem in fiber identification. These can be definitely identified by their pigment distribution. As picnometer measurements indicate that the density of both horsehair and bristle is approximately $1.29[10]$, quantitative data on the amount of each fiber in a mixture can be obtained by merely integrating the cross-sectional areas in photomicrograph.

Cross-sectional examination is, unfortunately, not applicable to white or very slightly pigmented fibers. Where only small amounts of pigment are present it is usually desirable to increase the section thickness to resolve the pigmentation pattern. The amount of light bristle or hair used in brushes, however, is not large. These observations indicate that where applicable the microscopic examination of cross sections is an accurate and rapid means of differentiating bristle and horsehair. Moreover, the techniques involved present no unusual difficulty, and the pigment distribution is a characteristic at the family level and not subject to significant change because of geographic location, type of hair, or location in the hair itself.

The author expresses his appreciation to Charles S. Cox of the Federal Trade Commission, John I. Hardy of the United States Department of Agriculture, and C. O. Handley, Jr. of the Smithsonian Institution for cooperation in the course of this work.

\section{References}

[1] Federal Trade Commission. Trade practice rules for the paint and varnish brush manufacturing industry (promulgated Jan. 14, 1939).

[2] M. Denison, Bristles and brushes (Dodd Mead and Co., New York, N. Y., 1949).

[3] Bureau of the Census, United States Imports of Merchandise for Consumption. Report No. FT 110 (1950).

[4] W. Von Bergen and W. Krauss, Textile fiber atlas (American Wool Handbook Co., New York, N. Y., 1942)

[5] W. Krauss, personal communication (1951)

[6] S. B. Newman, New technique for cutting very thin sections and its application to the electron microscopy of fibers, ASTM Bul. No. 163: 57-60 (1950).

[7] G. H. H. Tate, Mammals of eastern Asia, p. 310 to 315 (MacMillan Book Co., Inc., New York, N. Y., 1947).

[8] Federal Standard Stock Catalogue Section IV (Part 5), Federal Specification for Hair; Horse, Curled, C-H-111 (1935)

[9] T. M. P. Hardv and J. I. Hardv, Animal fibers used in brushes, U. S. Dept. Agr. Circular 802 (1949).

[10] Unpublished data. 


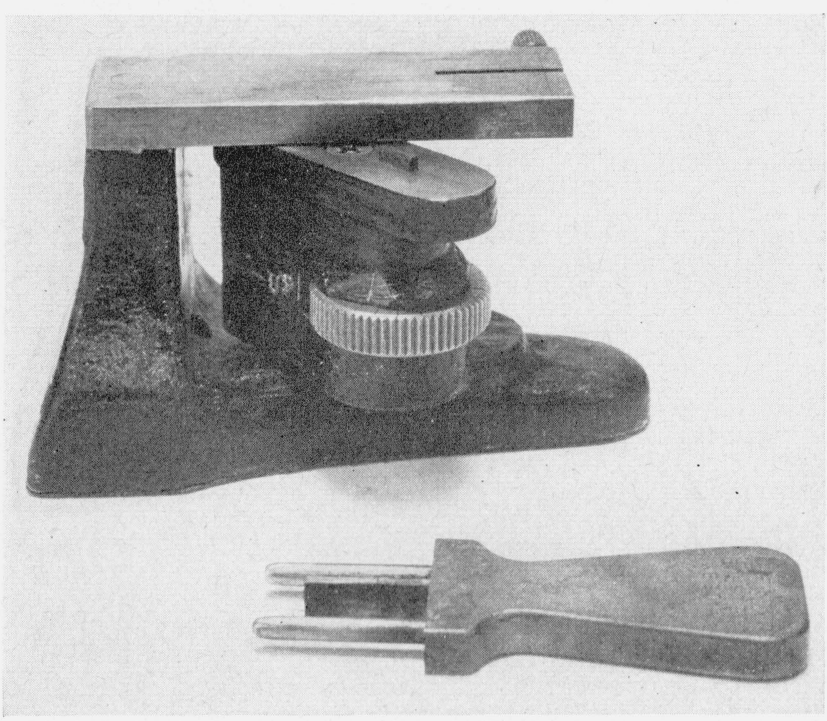

Frgure 1. Disassembled Hardy microtome.

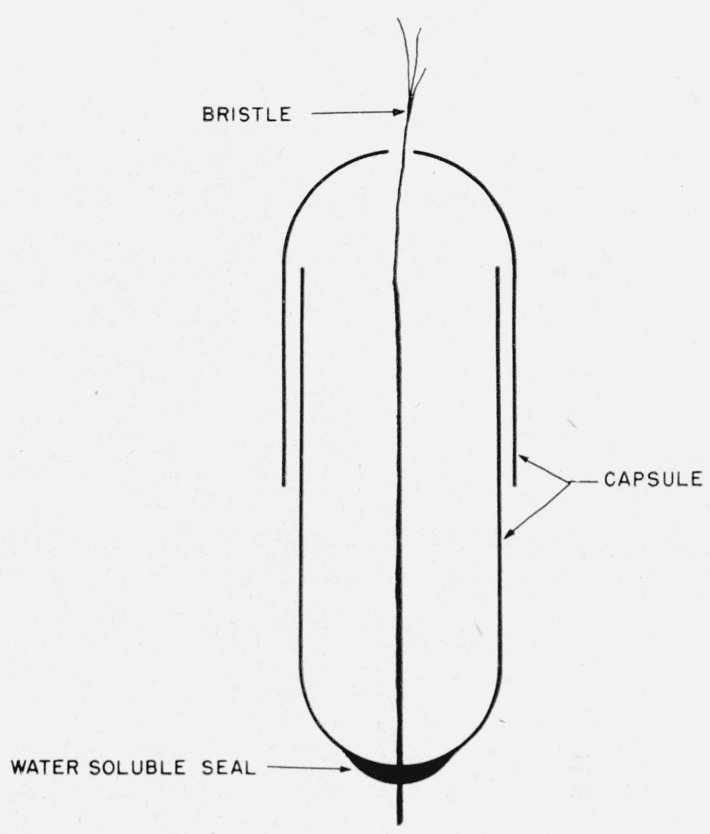

Figure 2. Schematic section of capsule embedding cell for single bristles.

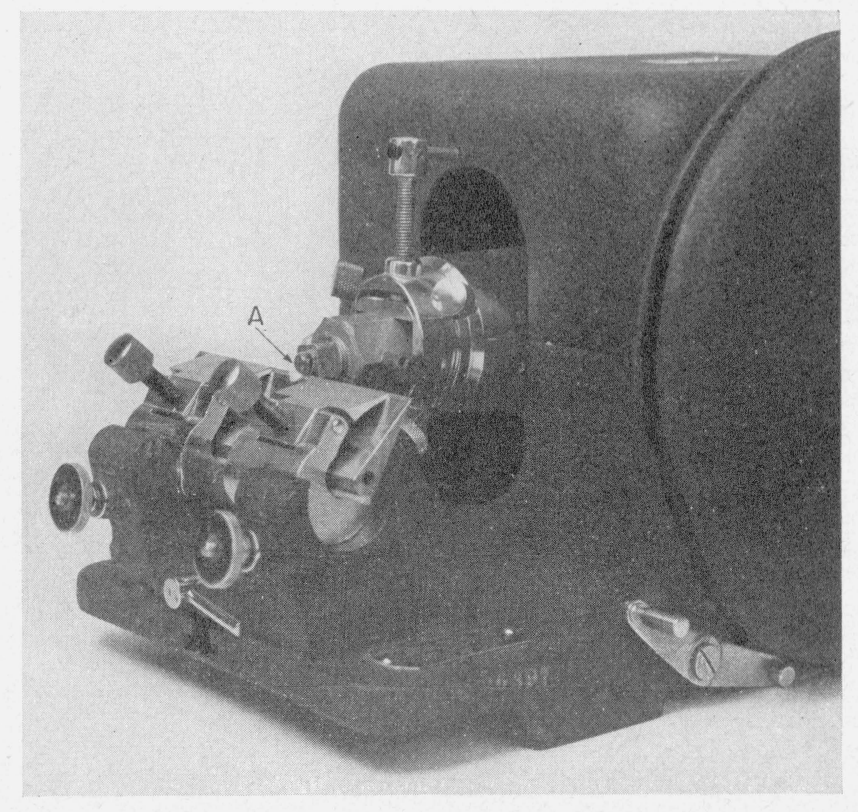

Figure 3. Sectioning single fibers.

A, Single bristle being sectioned in a rotary microtome. 

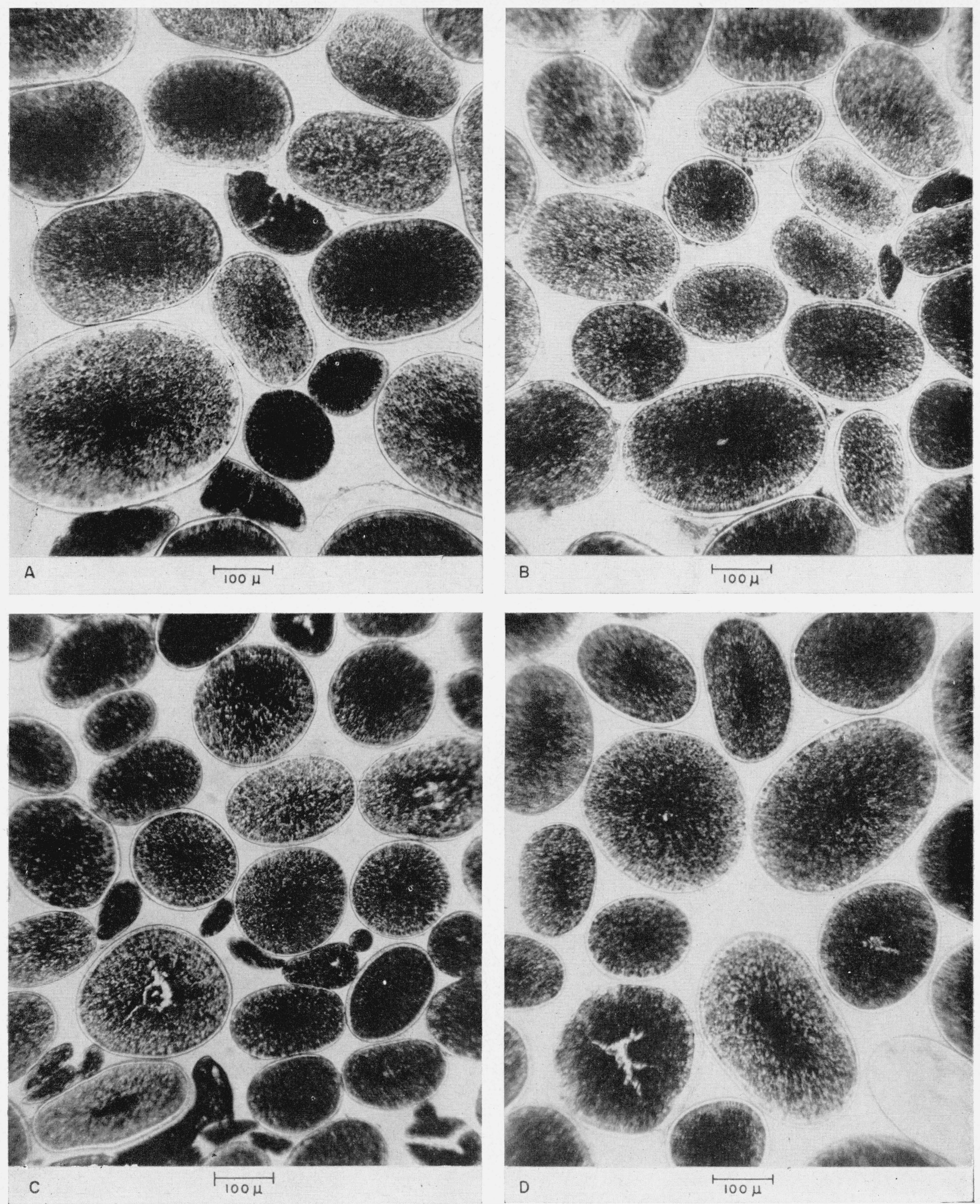

Figure 4. Cross sections of bristle from various sources.

A, Black Hankow received in 1936 from commercial source B; B, Black Hankow received in 1950 from commercial source A; C, random sample taken from a bristle brush; D, Ecuador, South America. 


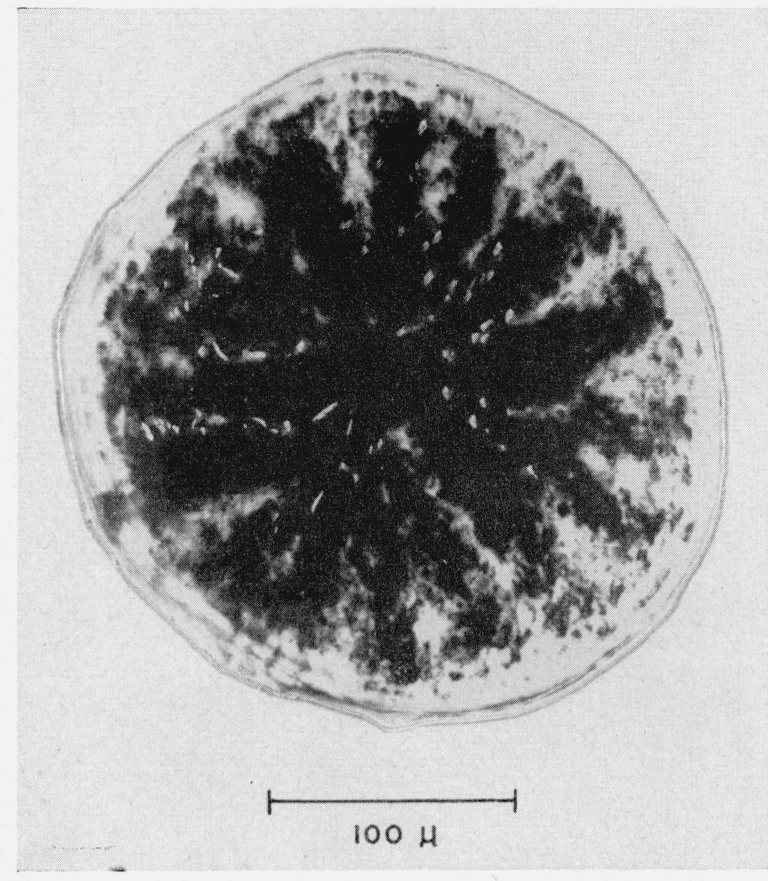

Figure 5. Cross section of a Persian bristle showing radiating bands of pigment.

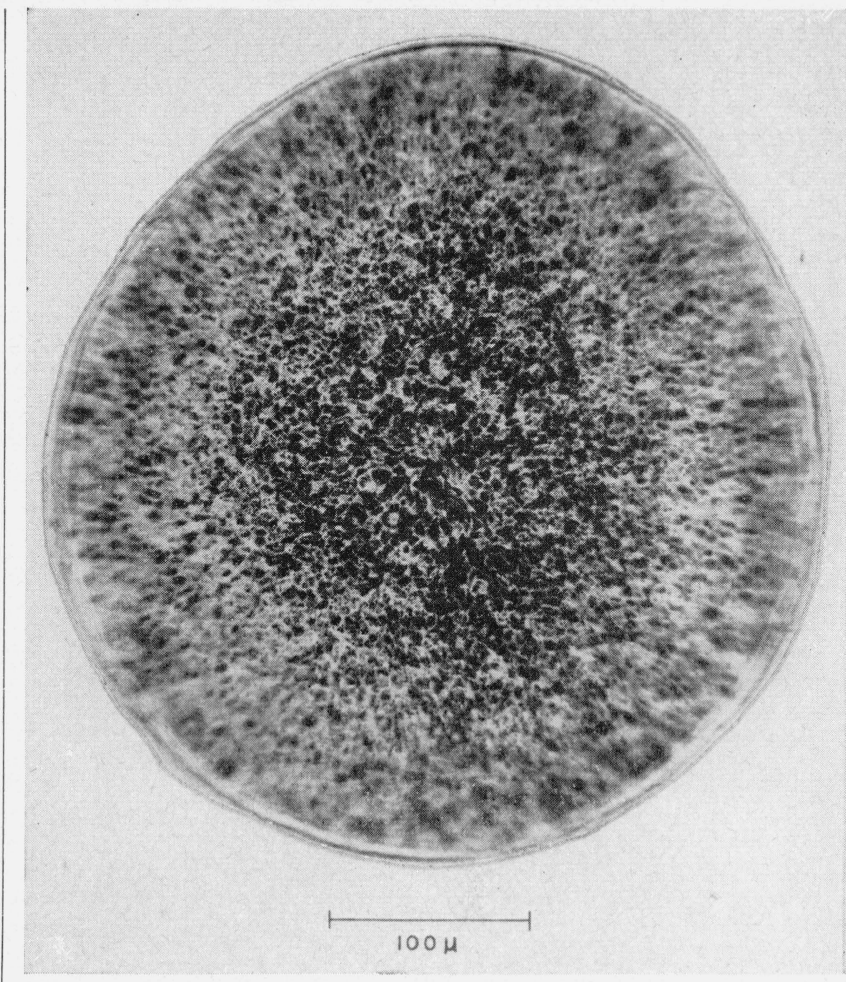

FIGURE 6. Cross section of a hair from Hylochoerus meinertzhageni (Suidae) showing hog-type distribution of pigment. From U. S. National Museum specimen 164627.

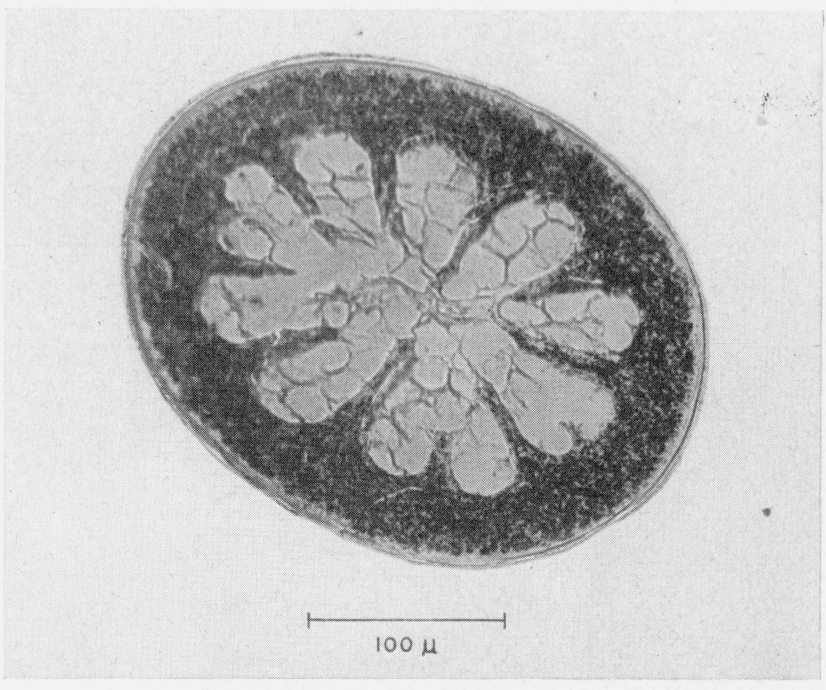

Figure 7. Cross section of hair from a peccary, Pecari angulatus crusniger.

From U. S. National Museum specimen 11710. 

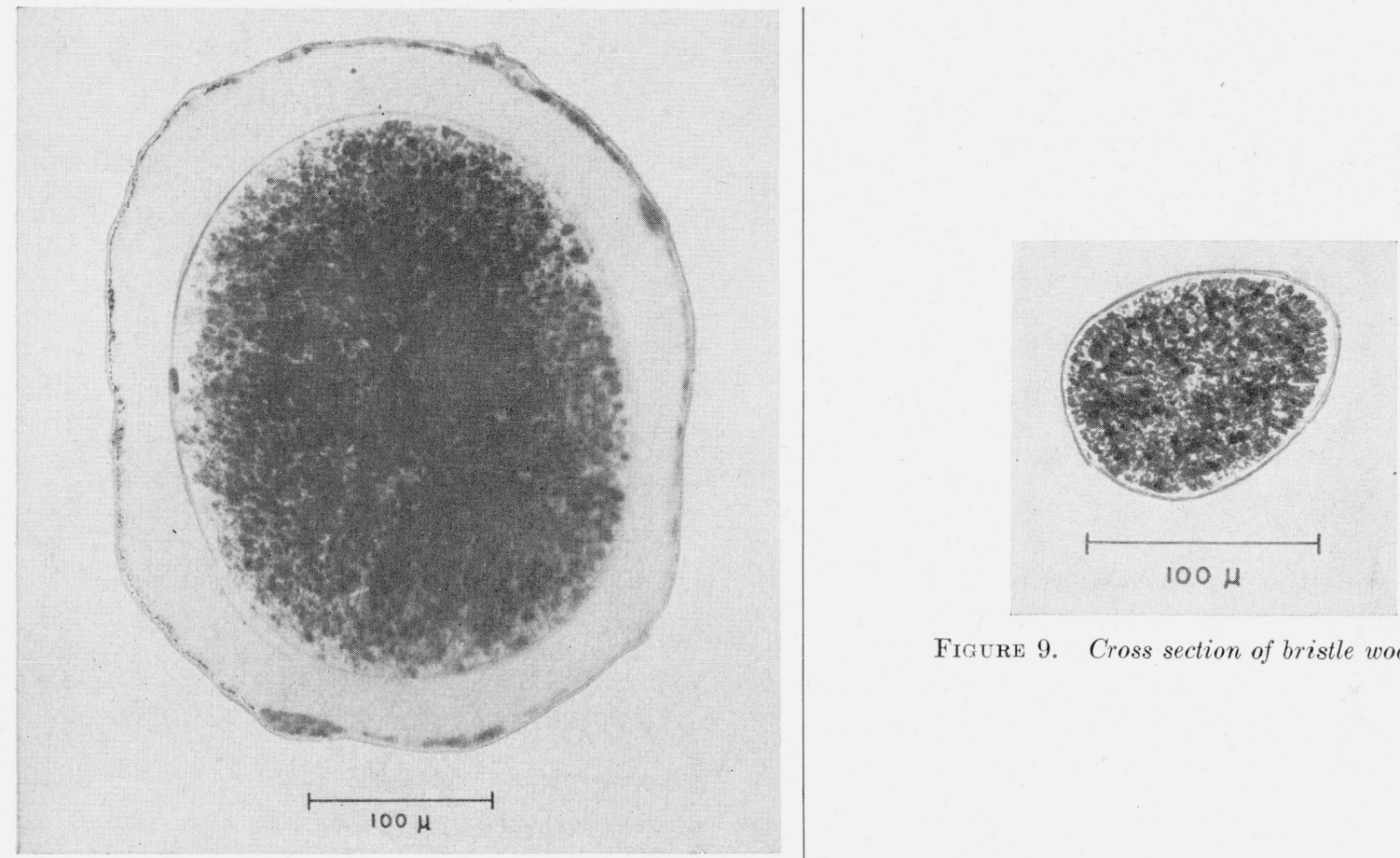

Figure 9. Cross section of bristle wool.

Figure 8. Section through the butt end of a black Hankow bristle showing the root sheath.

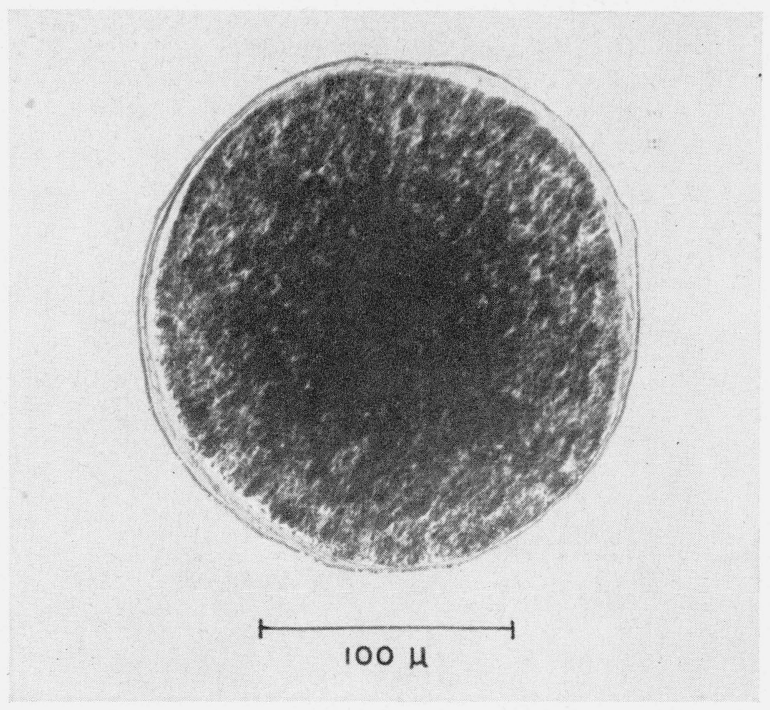

Figure 10. Cross section of bristle hair. 

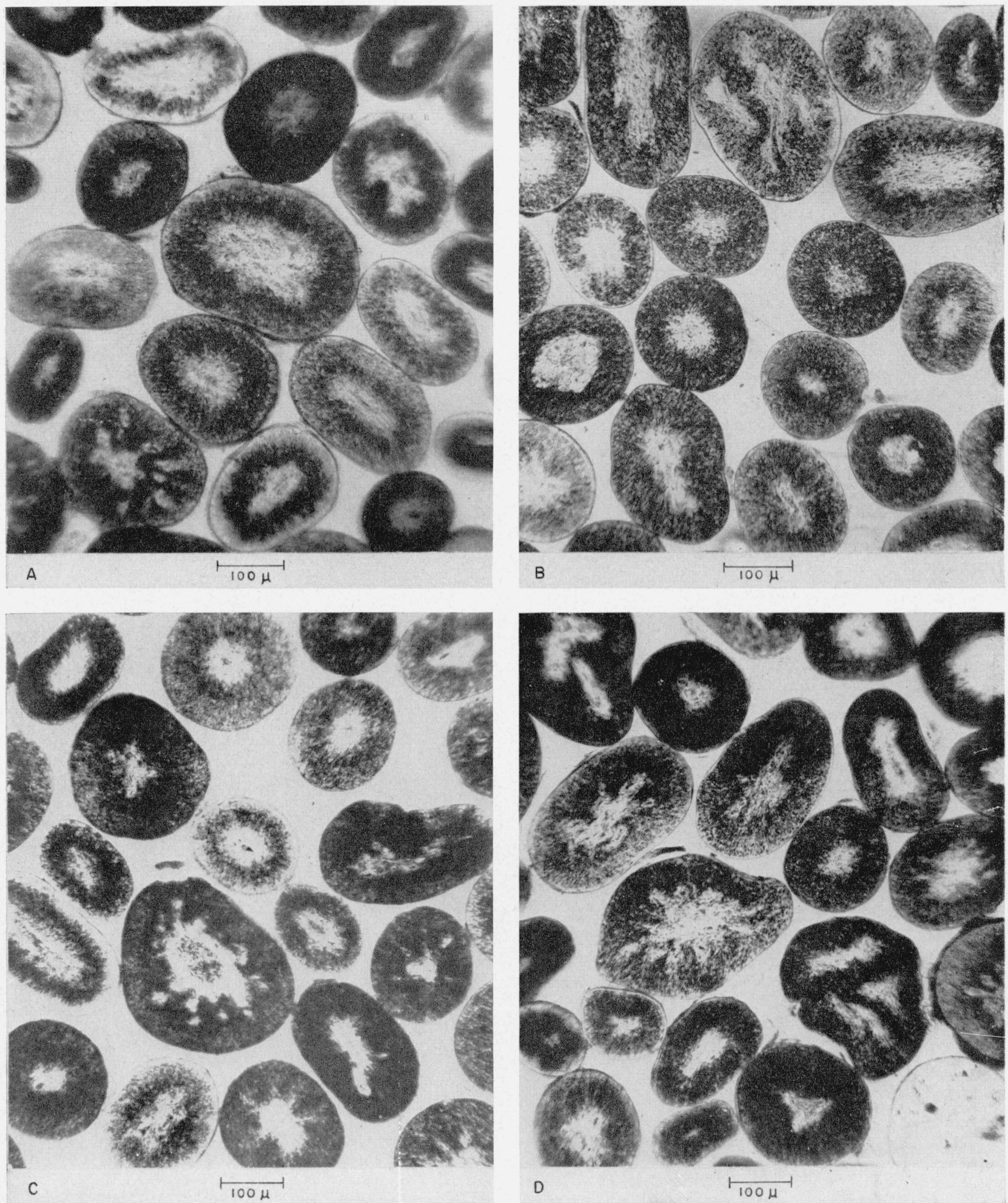

Figure 11. Cross sections of commercial horsehair.

A, Black Australian; B, regular medium quality black horsehair; C, No. 1 stiff quality black horsehair; D, No. 2 stiff quality black horsehair. 


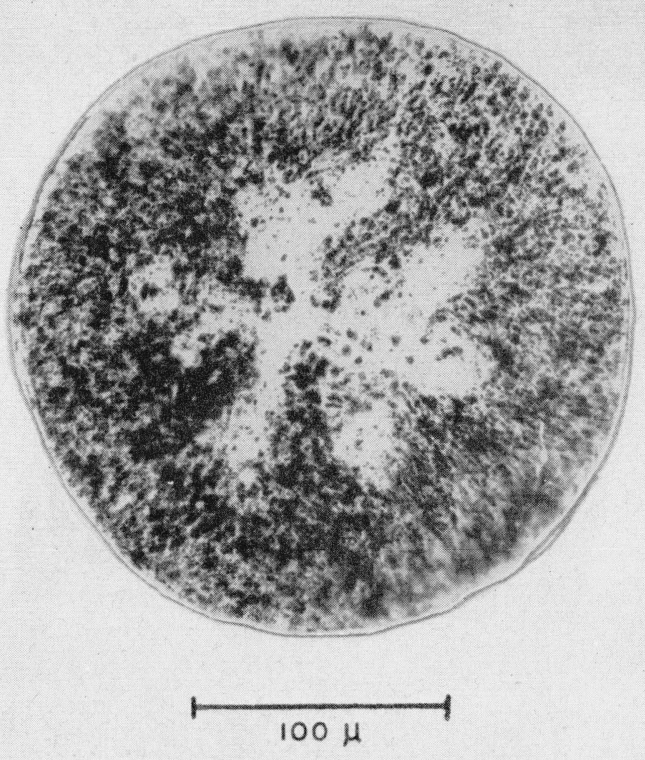

Figure 12. Cross section of a horse tail hair (Equus caballus) near the root end.

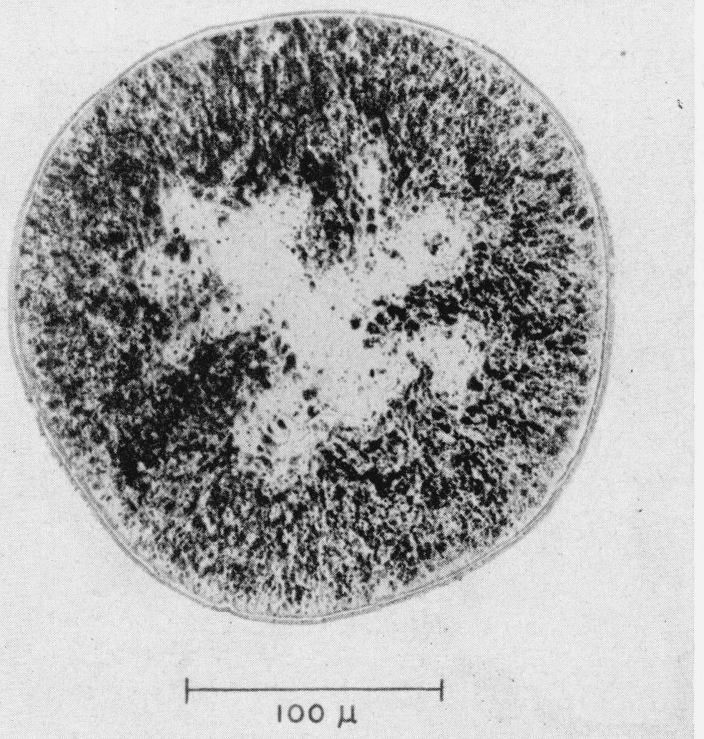

FIGURE 14. Cross section of the same hair as in figure 12 but from the distal end.

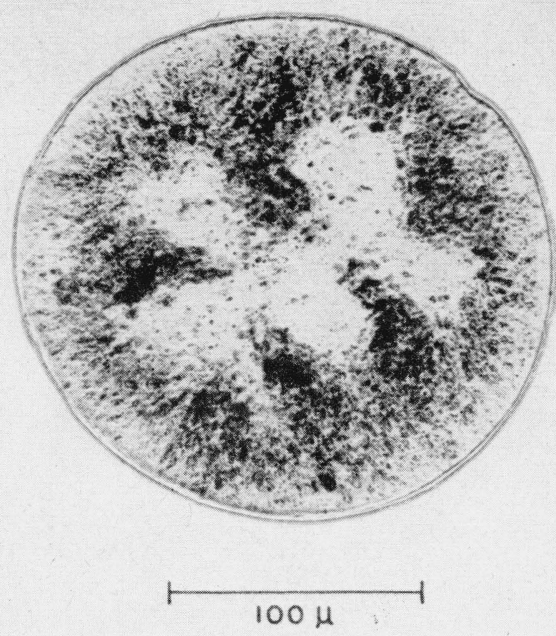

Figure 13. Cross section of the same hair as in figure 12 but from the middle of the length.

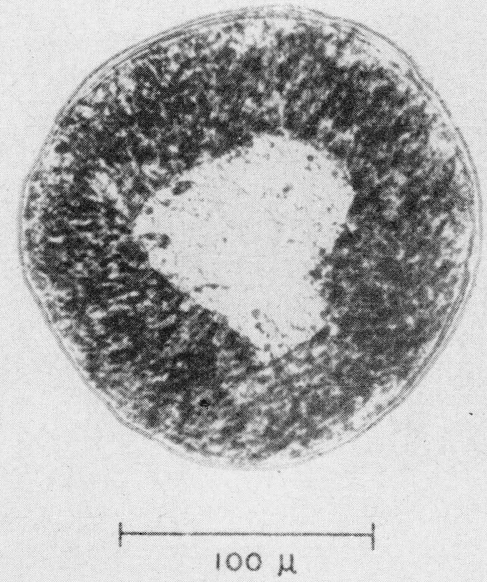

Figure 15. Cross section of a hair from Grevy's Zebra, Equus grevyi.

From U. S. National Museum specimen 163238

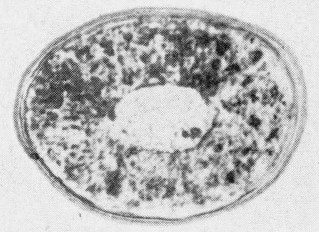

Fioure 16. Cross section of a hair from the wild horse, Equus przewalskii.

From U. S. National Museum specimen 260018.

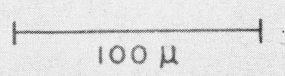




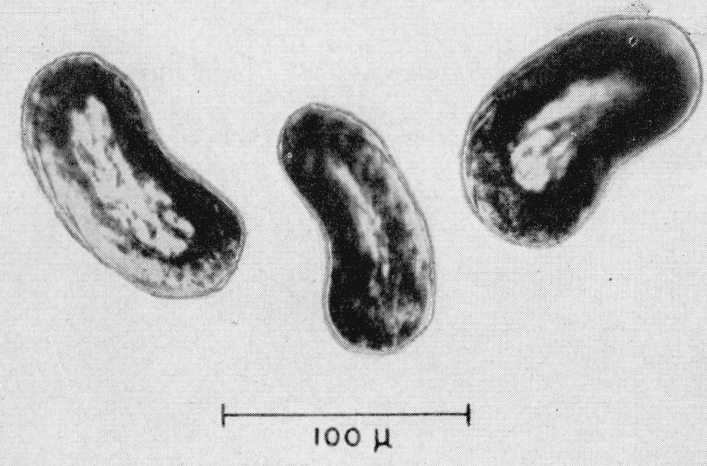

Figure 17. Cross section of a hair from the wild ass, Equus hemionus.

From U. S. National Museum specimen 84083.
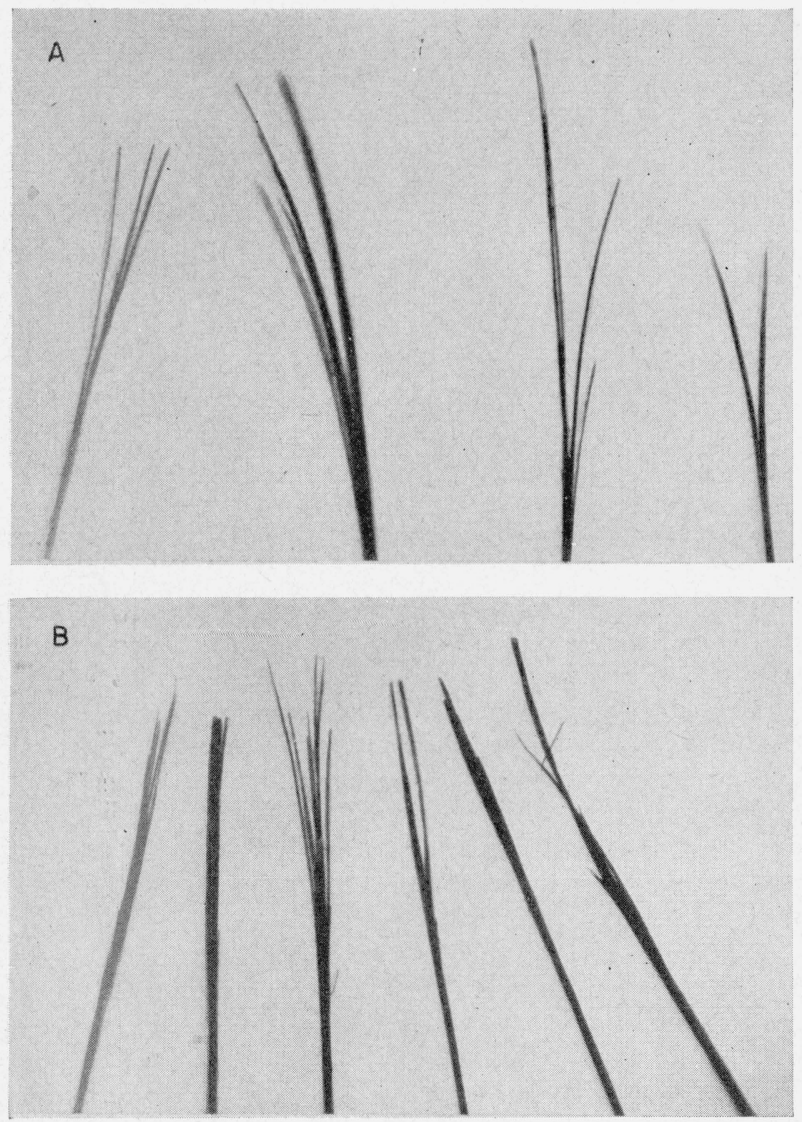

Figure 19. A, Natural bristle flags; B, artificially flagged Approximately $\times 6$ natural size. horsehair.

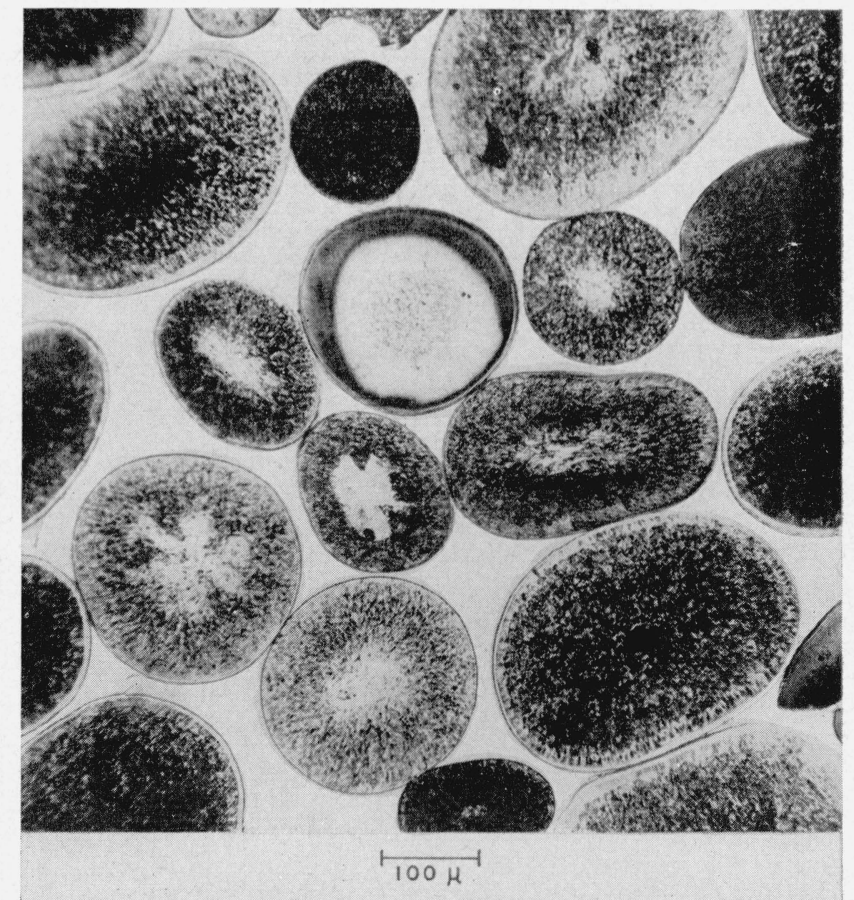

FIgURE 20. Cross section of fibers from a brush showing hor sehair and bristle.

Washington, December 28, 1951. 